\title{
Delivering the Transforming Care programme: a case of smoke and mirrors?
}

\author{
John L. Taylor
}

BJPsych Bulletin (2019) 43, 201-203, doi:10.1192/bjb.2019.3

Health and Life Sciences, Northumbria University, UK

Correspondence to John L. Taylor (john.taylor@ntw.nhs.uk)

First received 7 Nov 2018, accepted 4 Jan 2019

(c) The Author 2019. This is an Open Access article, distributed under the terms of the Creative Commons Attribution-NonCommercial-

NoDerivatives licence (http:// creativecommons.org/licenses/by-ncnd/4.0/), which permits non-

commercial re-use, distribution, and reproduction in any medium, provided the original work is unaltered and is properly cited. The written permission of Cambridge University Press must be obtained for commercial re-use or in order to create a derivative work.
Summary The Transforming Care national plan for England to develop community services and close hospital beds for people with intellectual disabilities and/or autism was published in October 2015 and is due to finish in March 2019. In this editorial the key plan objectives are evaluated, with particular reference to people with intellectual disabilities and/or autism who offend or are at risk of offending. The conclusion is that, to date, the plan has failed to meet its targets to reduce the number of inpatients with intellectual disabilities and/or autism and to invest in community services, and the number of patients in independent sector beds is increasing.

Declaration of interest The author is employed by Northumberland, Tyne and Wear National Health Service Foundation Trust, however the opinions expressed in this article are the author's own and do not reflect the views of the Trust.

Keywords Transforming Care; national plan; intellectual disabilities; autism; offenders.
'All political power is primarily an illusion... Mirrors and blue smoke, beautiful blue smoke rolling over the surface of highly polished mirrors...' (p. 33) ${ }^{1}$

\section{Transforming Care}

Building the Right Support ${ }^{2}$ is a national plan published in October 2015 by National Health Service (NHS) England and its local authority partners which aims to develop community services and close hospital beds for people with intellectual disabilities and autism 'who display behaviour that challenges' (p. 4). The plan includes the closure of $45-65 \%$ of local Clinical Commissioning Group-commissioned and $25-40 \%$ of NHS England-commissioned intellectual disability in-patient beds by the end of March 2019. The rationale for these numbers and timescale is unclear beyond what NHS commissioners and local authorities told the plan's authors 'they believe is possible', which was then 'sensechecked' against geographical variations in current in-patient service usage (p. 27). The money saved from these bed closures was to be reinvested in the development of community services.

The origin of this plan was the Winterbourne View scandal in 2011 which involved the systematic abuse of people with intellectual disabilities in an independent sector hospital unit in Bristol, England. ${ }^{3}$ Under pressure from politicians and stakeholder groups who claimed that the government had failed to deliver on its earlier promises, Simon Stevens - the chief executive of the NHS - committed to a 2 year intellectual disability hospital closure programme during a parliamentary select committee hearing on services for people with intellectual disabilities and challenging behaviour in February 2015. ${ }^{4}$ In relation to independent sector providers, Mr Stevens reassured the Public Accounts Committee, saying We cannot just have the situation where we simply reduce the NHS provision and instead it just flows over into third party providers that expand on the back of it.' (p. 17).

It can be seen that for the Transforming Care programme to meet the bed closure targets set out in the national plan, two fundamental things needed to happen: (a) substantial investment to strengthen established and develop new community services, and (b) a significant reduction in the number of patients residing in in-patient services.

These twin requirements can be taken as the acid test by which the success of the Transforming Care programme can be judged. It is timely to consider the extent to which these targets have been achieved as we are now in the final 3 months of the programme, which runs to the end of March 2019. Indeed, the national plan says 'Before the end of 2018, having built up community support and closed hundreds of beds, we will take stock and look at going further.' (p. 8). ${ }^{2}$

\section{Investment in community services}

The national plan is clear that investment in community services is essential to support people with intellectual 
disabilities and/or autism to have active lives in their own homes as members of the wider community. To date, however, little progress appears to have been made in building new community services to support the bed closure plans as envisaged in the plan. A National Audit Office (NAO) report stated, however, that 'Money is not yet being released from mental health hospitals quickly enough to help pay for extra community support.' (p. 9). ${ }^{5}$ The NAO report states that not enough community accommodation is being put in place to enable people to leave hospital and there has been little progress in achieving other programme objectives (e.g. workforce developments, hospital care closer to home and length of stay in hospital).

More recently, the Health Services Journal (HSJ) reported that information from fast-track areas indicated that implementation of the Transforming Care programme - which NHS England had said would be cost neutral - could lead to additional costs of more than $£ 100$ million per year. ${ }^{6}$ A report by Resonance, ${ }^{7}$ commissioned by the Transforming Care and Commissioning Steering Group, chaired by Sir Stephen Bubb, ${ }^{8}$ indicated that the expected savings to be made by moving from in-patient to community packages were between $£ 50000$ and $£ 125000$ per person per year. The $H S J J^{6}$ however, reported that sources from Transforming Care partnerships claimed that the actual cost of supporting people with very complex needs in the community 'can be more than $£ 250000$ a year, with the most expensive close to $£ 1 \mathrm{~m}$ '.

\section{Reducing the number of people in in-patient services}

Building the Right Support is explicit: at a minimum 35$50 \%$ of intellectual disability/autism beds will close by the end of March 2019. The programme uses 'Assuring Transformation' data, a commissioner-based return for patients with intellectual disabilities and/or autism in hospital settings that is published by NHS Digital. The national plan was published in October 2015 and stated that there were 2600 hospital in-patients at that time. The second Bubb report ${ }^{9}$ commented that Health and Social Care Information Centre (HSCIC) census data on intellectual disability (also known as learning disability in UK health services) indicated that the number was closer to 3500 . Assuring Transformation data rely on commissioner-based information, whereas the intellectual disability census uses information submitted by service providers. The $\mathrm{NAO}^{10}$ found the use of two unreconciled sets of data that produced different numbers of people in hospital beds to be unsatisfactory.

In its second report published in March 2017, the $\mathrm{NAO}^{5}$ was disappointed to find that this problem persisted: the Transforming Care programme's Assuring Transformation figures showed a fall in the number of hospital patients from 2835 in October 2015 to 2510 in December 2016, whereas HSCIC's new mental health services data set (MHSDS) figures showed an increase in in-patient numbers from 3110 in May 2016 to 3805 in November 2016. This disparity has continued with programme Assuring Transformation data ${ }^{11}$ published in March 2018 indicating 2415 people with intellectual disabilities and/or autism were in hospital at the end of February
2018, and MHSDS data ${ }^{12}$ published in February 2018 showing that the figure was 3575 .

Even if we simply look at the Transforming Care programme's preferred Assuring Transformation data since they were first published in March 2015, the number of people with intellectual disabilities and/or autism in hospital at the end of each monthly reporting period has changed little if one uses the like-for-like provisional data reported by commissioners each month. ${ }^{12}$ This shows that the number of in-patients reported in March 2015 was 2395 and the number at the end of February 2018 was 2415 - that is, an increase of just under 1\%. Yet, an NHS England spokesperson was quoted in the $H S J$ in April 2018 as saying 'Real progress is being made and the number of in-patients with a learning disability has fallen by 16 per cent since [March] $2015^{\prime}{ }^{6}$ In any event, it is clear that the programme will not result in the closure of 'hundreds of beds' and the freeing up of the 'tens of millions of pounds' promised in the national plan (p. 13). ${ }^{2}$ Perhaps as a consequence of these poor results to date, the NAO (in 2017) found that 'programme partners considered it likely that Partnerships would not [emphasis added] deliver the required reduction in bed numbers by 2019'. ${ }^{5}$ This is because of 'concerns about the credibility of the Partnerships' plans for bed closures, a lack of community infrastructure and an inability to discharge patients.' (p. 8).

\section{The impact of Transforming Care}

Because of the targets set by the national plan, commissioners are under pressure to move people out of hospital, even when appropriate community services, support and accommodation may not be available. This includes significant numbers of people who have committed criminal offences and have ongoing forensic-risk needs. As noted by the $\mathrm{NAO}^{5}$ in 2017, the imperative to close beds along with the lack of investment in community infrastructure and support can lead to people living in inappropriate settings. This will likely result in high levels of readmission. In 2016, on average, $25 \%$ of people with an intellectual disability and/ or autism admitted to hospital had been discharged from hospital within the previous 12 months. ${ }^{5}$

Possible unintended consequences of the policy to rapidly close NHS intellectual disability/autism beds before community services have been developed is that more offenders with intellectual disabilities and/or autism may be sent to prison or diverted to independent sector beds. ${ }^{13}$ In 2006 the independent sector provided $20 \%$ of all intellectual disability in-patient beds. ${ }^{14}$ This rose to $33 \%$ in 2010 and jumped to $52 \%$ in 2016 when this market was estimated to be worth $£ 284$ million in a report on in-patient healthcare economy for people with intellectual disabilities and/or autism entitled A Trade in People. ${ }^{14}$ It may be the case, therefore, that the increased marketisation of the provision of intellectual disability hospital beds is being facilitated by the closure of NHS beds through the Transforming Care programme. This is despite the available evidence showing that patients detained within independent sector beds are $30 \%$ more likely to experience assault and $60 \%$ more likely to be restrained than patients in NHS facilities. ${ }^{15}$ 


\section{Discussion and conclusions}

The Transforming Care programme is explicitly focused on closing all intellectual disability and autism hospital beds, despite there being no credible analysis or evidence presented in the national plan to support the closure programme. Underpinning this aim are assumptions that the hospital is always bad and community is always better. The second Bubb report tells us 'Hospital-based care should never be the preferred option for an individual' and providing adequate services in the community would prevent hospital admissions (p. 13). ${ }^{9}$ This is as wrong-headed as saying that people who require heart bypass surgery would never need to go into hospital for surgery if adequate support was provided for them to have the operation on their kitchen table. Essentially it is a discriminatory policy that will deny people with intellectual disabilities and/or autism who have complex needs - including those who present serious forensic risks to others - access to the specialist in-patient care, treatment and sanctuary that they need.

Putting these dubious assumptions to one side, the evidence available to date is that the programme is failing to deliver on its main aims. It has failed to significantly reduce the number of people with intellectual disabilities and/or autism in in-patient facilities. It has failed to invest tens of millions of pounds in community services as promised. And, despite the reassurances given by the NHS chief executive at the outset, the programme also appears to have resulted in increased use of independent sector hospital beds.

It is unsurprising, therefore, that in 2017 the $\mathrm{NAO}^{5}$ concluded that the programme is not providing value for money. We will have to wait and see what NHS England decides will follow the national plan which is due to be completed in March 2019. Perhaps the evaluation of the programme we were promised before the end of 2018 will dispel some of the smoke and mirrors currently clouding our view of this ideologically driven programme that is having a disproportionate effect on the care and safety of offenders with intellectual disabilities. Unfortunately, there is no sign that this evaluation is underway or that any critical analysis of the programme's outcomes is likely to forthcoming in the foreseeable future.

\section{About the author}

John L. Taylor is a Professor of Clinical Psychology at Northumbria University, UK.

\section{References}

1 Breslin J. How the Good Guys Finally Won, Notes from an Impeachment Summer. Viking, 1975.

2 National Health Service (NHS) England. Building the Right Support: A National Plan to Develop Community Services and Close Inpatient Facilities for People with a Learning Disability and/or Autism Who Display Behaviour that Challenges, Including Those with a Mental Health Condition. NHS, 2015 (https://www.england.nhs.uk/wp-content/ uploads/2015/10/ld-nat-imp-plan-oct15.pdf)

3 Department of Health (DoH). Transforming Care: A National Response to Winterbourne View Hospital. DoH, 2012.

4 Public Accounts Committee. Oral Evidence: Care Services for People with Learning Disabilities and Challenging Behaviour. HC 973, Monday, 9 February. Public Accounts Committee, 2015.

5 National Audit Office. Local Support for People with a Learning Disability: Report by the Comptroller and Auditor General. National Audit Office, 2017

6 Moore A. National learning disabilities programme 'leading to unplanned costs'. Health Serv J 2018. Available at www.hsj.co.uk/ finance-and-efficiency/national-learning-disabilities-programme-leadingto-unplanned-costs/7022111.article.

7 Resonance. Winterbourne View and Social Investment. Resonance, 2014 Available at http://resonance.ltd.uk/wp-content/uploads/2016/06/ Winterbourne_View_Social_Investment_Report_26_Nov_2014.pdf.

8 Bubb S. Winterbourne View: Time for Change. Transforming Care and Commissioning Steering Group, 2014. Available at https://www.england. nhs.uk/wp-content/uploads/2014/11/transforming-commissioningservices.pdf.

9 ACEVO. Time for Change: The Challenge Ahead. AVECO, 2016. [Known as the second Bubb report.]

10 National Audit Office. Care Services for People with Learning Disabilities and Challenging Behaviour, Session 2014-15, HC 1028. National Audit Office, 2015.

11 National Health Service (NHS) Digital. Learning Disability Services Monthly Statistics England Commissioner Census (Assuring Transformation) - February 2018 Provisional Statistics. NHS Digital, 2018. Available at https://files. digital.nhs.uk/pdf/8/9/ldsm-feb-18-main-report.pdf.

12 National Health Service (NHS) Digital. Learning Disability Services Monthly Statistics: Mental Health Services Dataset: Learning Disability and Autism Statistics - February 2018, Experimental. NHS Digital, 2018. Available at https://files.digital.nhs.uk/BO/AE5F14/MHSDS\%20Monthly\%20February \%202018\%20LDA\%20Main\%20Report.pdf.

13 Taylor JL, McKinnon I, Thorpe I, Gillmer BT. The impact of Transforming Care on the care and safety of patients with learning disabilities and forensic needs. Br J Psychiatry Bull 2017; 41: 205-8.

14 Brown M, James E, Hatton C. A Trade in People: The Inpatient Healthcare Economy for People with Learning Disabilities and/or Autism Spectrum Disorder. Lancaster University: Centre for Disability Research, 2017.

15 Glover G, Olson V. Assessment and Treatment Units and Other Specialist Inpatient Care for People with Learning Disabilities in the Count-Me-In surveys, 2006 to 2010. Improving Health and Lives: Learning Disabilities Observatory, 2012.

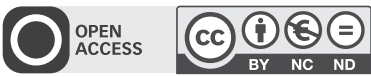

